\title{
Chondrocyte Production of Pro-Inflammatory Chemokine MCP-1 (CCL-2) and Prostaglandin E-2 Is Inhibited by Avocado/Soybean Unsaponifiables, Glucosamine, Chondroitin Sulfate Combination
}

\author{
Erica J. Secor'1, Mark W. Grzanna², Ann M. Rashmir-Raven³, Carmelita G. Frondoza ${ }^{2,4,5^{*}}$ \\ ${ }^{1}$ College of Veterinary Medicine, Cornell University, Ithaca, New York, USA \\ ${ }^{2}$ Department of Research and Development, Nutramax Laboratories Inc., Edgewood, USA \\ ${ }^{3}$ College of Veterinary Medicine, Michigan State University, East Lansing, USA \\ ${ }^{4}$ Department of Orthopedic Surgery, Johns Hopkins University, Baltimore, USA \\ ${ }^{5}$ College of Veterinary Medicine, Mississippi State University, Starkville, USA \\ Email: *cgfrondo@jhmi.edu
}

How to cite this paper: Secor, E.J., Grzanna, M.W., Rashmir-Raven, A.M. and Frondoza, C.G. (2018) Chondrocyte Production of Pro-Inflammatory Chemokine MCP-1 (CCL-2) and Prostaglandin E-2 Is Inhibited by Avocado/Soybean Unsaponifiables, Glucosamine, Chondroitin Sulfate Combination. Pharmacology \& Pharmacy, 9, 10-26.

https://doi.org/10.4236/pp.2018.91002

Received: November 29, 2017

Accepted: January 9, 2018

Published: January 12, 2018

Copyright (c) 2018 by authors and Scientific Research Publishing Inc. This work is licensed under the Creative Commons Attribution International License (CC BY 4.0).

http://creativecommons.org/licenses/by/4.0/ (c) $\underset{\mathrm{EY}}{\mathrm{EY}}$ Open Access

\begin{abstract}
Osteoarthritis (OA) is a chronic, painful disease affecting articulating joints in man and animals. It is characterized by cartilage breakdown, bone remodeling, osteophyte formation and joint inflammation. Currently used non-steroidal anti-inflammatory drugs for the management of OA are known to have deleterious side effects. To address the need for alternatives, we evaluated the anti-inflammatory effects of a combination of avocado/soybean unsaponifiables (ASU), glucosamine (GLU) and chondroitin sulfate (CS) by measuring chemokine MCP-1 (monocyte chemoattractant protein 1, CCL2) and prostaglandin E-2 $\left(\mathrm{PGE}_{2}\right)$ in stimulated chondrocytes. As the only cellular constituents of cartilage, chondrocytes are the source of pro-inflammatory mediators that play critical roles in the pathogenesis of OA. Chondrocytes were incubated: with: 1) control media, 2) [ASU + GLU + CS] combination, or 3) Phenylbutazone (PBZ) for 24 hours. Cells were next stimulated with IL- $1 \beta$ or LPS for another $24 \mathrm{hrs}$. MCP-1 and $\mathrm{PGE}_{2}$ from supernatants were quantitated by immunoassay. Another set of chondrocytes seeded in chamber slides were stimulated with IL- $1 \beta$ for 1 hour and then immunostained for NF- $\kappa$ B. Chondrocytes stimulated with IL- $1 \beta$ or LPS significantly increased MCP-1 and $\mathrm{PGE}_{2}$ production which were significantly reduced after treatment with [ASU + GLU + CS]. In contrast, PBZ significantly reduced PGE $_{2}$ but not MCP-1 production. IL- $1 \beta$ stimulation induced nuclear translocation of NF- $\kappa \mathrm{B}$, which
\end{abstract}


was inhibited by pre-treatment with either [ASU + GLU + CS] or PBZ. The present study provides evidence that the production of MCP-1 by chondrocytes can be inhibited by the combination of [ASU + GLU + CS] but not by $\mathrm{PBZ}$. In contrast, $\mathrm{PGE}_{2}$ production was inhibited by either treatment suggesting that the production of $\mathrm{MCP}-1$ and $\mathrm{PGE}_{2}$ could be independently regulated. The finding of distinct effects of [ASU + GLU + CS] on MCP-1 and $\mathrm{PGE}_{2}$ synthesis supports a scientific rationale for a multimodal treatment approach in the management of OA.

\section{Keywords}

Inflammation, Chondrocytes, Avocado/Soybean Unsaponifiables, Glucosamine, Chondroitin Sulfate

\section{Introduction}

Osteoarthritis (OA) is a painful, chronic degenerative disease which affects the quality of life in both man and animals [1]. OA is characterized by cartilage breakdown, bone remodeling, osteophyte formation and joint inflammation. Humans and animals such as horses afflicted with OA suffer from debilitating morbidity [2]. OA in horses accounts for substantial monetary loss in the equine industry. It is estimated that $60 \%$ of lameness problems in horses are due to OA [3]. Approximately one third of 2 and 3-year old thoroughbred racehorses have macroscopic and histologic changes of the metacarpophalangeal joint associated with OA [4]. Humans and horses have similar joint volume, structure and biomechanical function [5] [6]. Their articular cartilage also exhibits similar cellular and molecular characteristics [5] [6]. Because of their common structural, functional and cellular characteristics, horses have been used as an in vivo model for studying human OA. Equine joint tissues such as cartilage and their constituent chondrocytes have also been beneficial as models for in vitro studies [7] [8] [9] [10] [11].

Pro-inflammatory mediators including prostaglandins (PG), cytokines, and chemokines play important roles in the pathogenesis of OA [12]-[26]. $\mathrm{PGE}_{2}$, interleukin (IL)- $1 \beta$, IL-6, and tumor necrosis factor (TNF)- $\alpha$ are well documented mediators of chronic pain and cartilage degradation in OA [12]-[26]. More recently, chemokines including MCP-1 (CCL2) and their receptors have been recognized as important players in OA pathogenesis [17]-[26]. Stimulation of human chondrocytes with IL- $1 \beta$ or TNF- $\alpha$ results in upregulation of MCP-1 gene expression compared to untreated controls [21]. In addition, there is evidence that MCP-1 contributes to cartilage matrix degeneration by increasing secretion of matrix metalloproteinase (MMP)-3 by chondrocytes [18]. MCP-1 as a key mediator of chronic pain has also been reported. Knockout mice with deleted MCP-1 receptor have been used to define this chemokine as a factor in nociception. While acute pain behavior is relatively unchanged in these animals, hyper- 
algesia is inhibited [21]. Administration of exogenous MCP-1 is seen to increase firing of dorsal root ganglia neurons, leading to neuronal hyperexcitability and neuropathic pain [22]. Studies also reinforced the role of MCP-1 as a mediator of osteoarthritic pain [17]-[26]. In addition, increased levels of MCP-1 in situ appear to correlate with the severity of the disease. These observations strengthen the possibility that MCP-1 plays a role in chronic pain and hyperalgesia.

Evidence supporting the role of pro-inflammatory molecules such as prostaglandins, cytokines and chemokines in the pathogenesis of OA led to the use of non-steroidal anti-inflammatory drugs (NSAIDs). These drugs help ease the pain and alleviate symptoms in OA patients but do not modify disease progression. Moreover, NSAIDs are associated with deleterious side effects affecting cardiovascular, gastrointestinal, renal and hepatic systems [27]. NSAIDs that ablate $\mathrm{PGE}_{2}$ production also disrupt bone healing and fracture repair [28] [29] [30]. Awareness of the adverse effects of NSAIDs has prompted the need to evaluate complementary and alternative agents for the safe management of OA. Non-pharmacologic agents that have been evaluated include glucosamine (GLU), chondroitin sulfate (CS) and avocado/soybean unsaponifiables (ASU) alone or in combination. ASU, GLU and CS have been documented to reduce inflammation in vitro [9] [10] [11], [31]-[38], and in vivo [39]-[46]. These agents have been reported to ameliorate $\mathrm{OA}$ in man and animals with minimal adverse side effects [39]-[46]. The molecular mechanism behind the beneficial effects of ASU, GLU and CS has been attributed to their ability to inhibit activation of NF- $\kappa \mathrm{B}$ transcription factor [47]-[52]. When activated, NF- $\kappa \mathrm{B}$ translocates from the $c y-$ toplasm to the nucleus which induces the expression of pro-inflammatory genes and catabolic enzymes that break down cartilage [47]-[52].

To address the need for safe alternative anti-inflammatory agents, this study was conducted to determine whether the combination of ASU, GLU and CS will

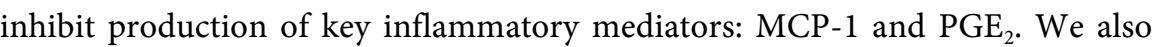
determined whether production of these pro-inflammatory mediators will similarly be inhibited by the NSAID, phenylbutazone (PBZ). Using an in vitro equine chondrocyte culture model, we observed that the [ASU + GLU + CS] combination inhibited production of both $\mathrm{MCP}-1$ and $\mathrm{PGE}_{2}$ while $\mathrm{PBZ}$ suppressed $\mathrm{PGE}_{2}$ but not MCP-1. Identifying compounds that inhibit both the chemokine MCP-1 and $\mathrm{PGE}_{2}$ in the osteoarthritic joint may offer a more effective therapeutic approach.

\section{Materials and Methods}

\subsection{Isolation of Equine Chondrocytes}

Articular cartilage was harvested from the radiocarpal and tibiotarsal joints of apparently healthy horses of unknown age, sex, or breed. The horses used in this study were obtained from commercial sources (Celsis In Vitro Technologies, Baltimore, MD) and one of the authors (ARR). For animals obtained by ARR, animals were euthanized for reasons unrelated to this study in compliance with 
Michigan State University's Institutional Animal Care and Use Committee. All harvested articular cartilage appeared smooth, glassy, and without macroscopic abnormalities. Cartilage was aseptically harvested, cut into $1-5 \mathrm{~mm}^{2}$ pieces, and digested with type II collagenase medium (10,000 U/L, Gibco, Invitrogen, Carlsbad, $\mathrm{CA}, \mathrm{USA}$ ) at $37^{\circ} \mathrm{C}, 5 \% \mathrm{CO}_{2}$ for 12 - 18 hours and chondrocytes were isolated as previously described [9].

\subsection{Treatment Design}

Cells were seeded in flasks, and allowed to grow to confluency in control media consisting of Dulbeccos' Modified Eagle's basal medium (Sigma; St. Louis, MO, USA) supplemented with $10 \% \mathrm{v} / \mathrm{v}$ fetal bovine serum (Gemini Bio-Products; Woodland, CA, USA), $300 \mathrm{mg} / \mathrm{ml} \mathrm{L}$-glutamine (Sigma), $30 \mathrm{mg} / \mathrm{ml}$ antibiotic/antimycotic (Sigma), and $3.7 \mathrm{~g} / \mathrm{L}$ sodium bicarbonate (Sigma), $\mathrm{pH} 7.4 \mathrm{at} 37^{\circ} \mathrm{C}$, $5 \% \mathrm{CO}_{2}$ [9]. Chondrocytes were used at passage $2-4$. Chondrocytes were seeded in 6-well plates at $5 \times 10^{6}$ cells/well, and incubated at $37^{\circ} \mathrm{C}, 5 \% \mathrm{CO}_{2}$ for 24 hours. Chondrocytes were then pre-treated with 1) control media, 2) [ASU $(\mathrm{NMX1000}, 8.3 \mu \mathrm{g} / \mathrm{mL})+\mathrm{GLU}(\mathrm{FCHG} 49 \AA, 11 \mu \mathrm{g} / \mathrm{mL})+\mathrm{CS}(\mathrm{TRH} 122 \AA, 20$ $\mu \mathrm{g} / \mathrm{mL}$ )] (Nutramax Laboratories, Inc., Edgewood, MD, USA), or 3) PBZ (4 $\mu \mathrm{g} / \mathrm{mL}$, Sigma-Aldrich, St. Louis, MO, USA) for an additional 24 hours. The concentrations of ASU, GLU, CS and PBZ used in the present study were previously reported to have significant anti-inflammatory effects and are clinically relevant [39]-[46]. Cells were then activated for 24 hours with IL-1 $\beta(10 \mathrm{ng} / \mathrm{mL}$, R\&D Systems, Minneapolis, MN, USA) or lipopolysaccharide (LPS, $1 \mathrm{ng} / \mathrm{mL}$, Sigma-Aldrich). Supernatant was collected and stored at $-80^{\circ} \mathrm{C}$ until assays were performed. Nine chondrocyte lines at passage $2-4$ from different horses were used and experiments were performed in triplicate.

\subsection{Collagen and Aggrecan Immunofluorescence}

Chondrocyte phenotype was characterized by immunofluorescence staining for collagen and aggrecan [9]. Chondrocytes were seeded at $1 \times 10^{4}$ cells/well on 8-well chambered slides (Fisher Scientific, Waltham, MA, USA) and incubated for 24 hours at $37^{\circ} \mathrm{C}, 5 \% \mathrm{CO}_{2}$. Cells were fixed with $10 \% \mathrm{v} / \mathrm{v}$ formalin (Thermo, Fisher Scientific) for 20 minutes and washed four times with 1x phosphate buffered saline (PBS, Gibco, Invitrogen). To prevent non-specific binding, a blocking solution (Gibco, Invitrogen) was applied and incubated for 30 minutes, followed by a 5 minute wash using PBS. Fixed cells were double stained for type I and type II collagen using a cocktail containing a goat anti-type I antibody (Southern Biotechnology Associates, Birmingham, AL, USA) diluted 1:500 and a mouse monoclonal anti-type II (Calbiochem, La Jolla, CA, USA) diluted 1:50 in PBS containing $0.05 \%$ Triton X-100. Cells were incubated overnight at $4^{\circ} \mathrm{C}$ and then washed 3 times with PBS for 5 minutes each.

For aggrecan immunostaining, fixed chondrocyte-seeded 8-well chambered cover glass slides were incubated with a blocker diluent solution at room temperature for 30 minutes (Gibco Invitrogen) to prevent non-specific binding. 
Slides were washed for 5 minutes with PBS and then incubated overnight at $4^{\circ} \mathrm{C}$ with mouse monoclonal anti-aggrecan (U.S. Biological, Swampscott, MA, USA) diluted 1:20 in PBS. Cells were washed 3 times with PBS then incubated with Alexa Fluor 488 donkey anti-mouse IgG (Gibco Invitrogen) and Alexa Fluor 594 donkey anti-goat IgG for 2 hours at room temperature with gentle agitation. Slides were washed 3 times with PBS and nuclei were stained with DAPI (Gibco Invitrogen) for 30 minutes as described above. Staining was analyzed using a Nikon epifluorescence TE 200 microscope and digital images were captured with a digital camera (Nikon Spot Camera, USA).

\subsection{Determination of NF- $\kappa$ B Nuclear Translocation Using Immunofluorescence}

Chondrocytes were seeded on 8-well chamber slides as described above. Cells were incubated at $37^{\circ} \mathrm{C}, 5 \% \mathrm{CO}_{2}$ overnight with 1) control media, 2) [ASU $(\mathrm{NMX1000}, 8.3 \mu \mathrm{g} / \mathrm{mL})+\mathrm{GLU}(\mathrm{FCHG} 49 \AA, 11 \mu \mathrm{g} / \mathrm{mL})+\mathrm{CS}(\mathrm{TRH} 122 \AA, 20$ $\mu \mathrm{g} / \mathrm{mL})]$, or 3$)$ PBZ $(4 \mu \mathrm{g} / \mathrm{mL})$. Cells were activated for 1 hour with IL-1 $\beta$ (10 ng/mL). Rabbit anti-NF- $\kappa$ B (Santa Cruz Biotechnology, Santa Cruz, CA, USA) was applied to the cells and incubated overnight at $4^{\circ} \mathrm{C}$. Slides were washed with $1 \mathrm{x}$ PBS, and a secondary donkey anti-rabbit IgG antibody labeled with Alexa Fluor-488 (Invitrogen) was applied for 2 hours. Cells were washed and analyzed using a Nikon epifluorescence TE 200 microscope and digital images were captured with a digital camera (Nikon Spot Camera, USA).

\subsection{MCP-1 and $\mathrm{PGE}_{2}$ Immunoassay (ELISA)}

MCP-1 and PGE 2 concentrations were determined in cell culture supernatant using commercially available ELISA kits (Equine CCL2 (MCP-1) VetSet, Kingfisher Biotech Inc., St. Paul, MN, USA and Prostaglandin E2 Parameter Assay Kit, R\&D Systems). All assays were run according to manufacturers' instructions and a standard was run in parallel to samples during each assay. Optical density was measured immediately using the SpectraMAX 340 microplate reader (Molecular Devices, Sunnyvale, CA, USA) at $450 \mathrm{~nm}$ with wavelength correction at $540 \mathrm{~nm}$.

\subsection{Statistical Analysis}

Pair-wise multiple comparisons were performed using one-way ANOVA, Tukey post-hoc using SigmaStat statistical software (Windows Version 3.11), where p < 0.05 was considered statistically significant.

\section{Results}

\subsection{Chondrocyte Phenotype Characterization}

Chondrocytes in monolayer culture showed immunostaining for collagen (Figure 1, top image) and aggrecan (Figure 1, bottom image). At passage 2 and 3 , some chondrocytes showed only type II collagen immunostaining. A few cells 

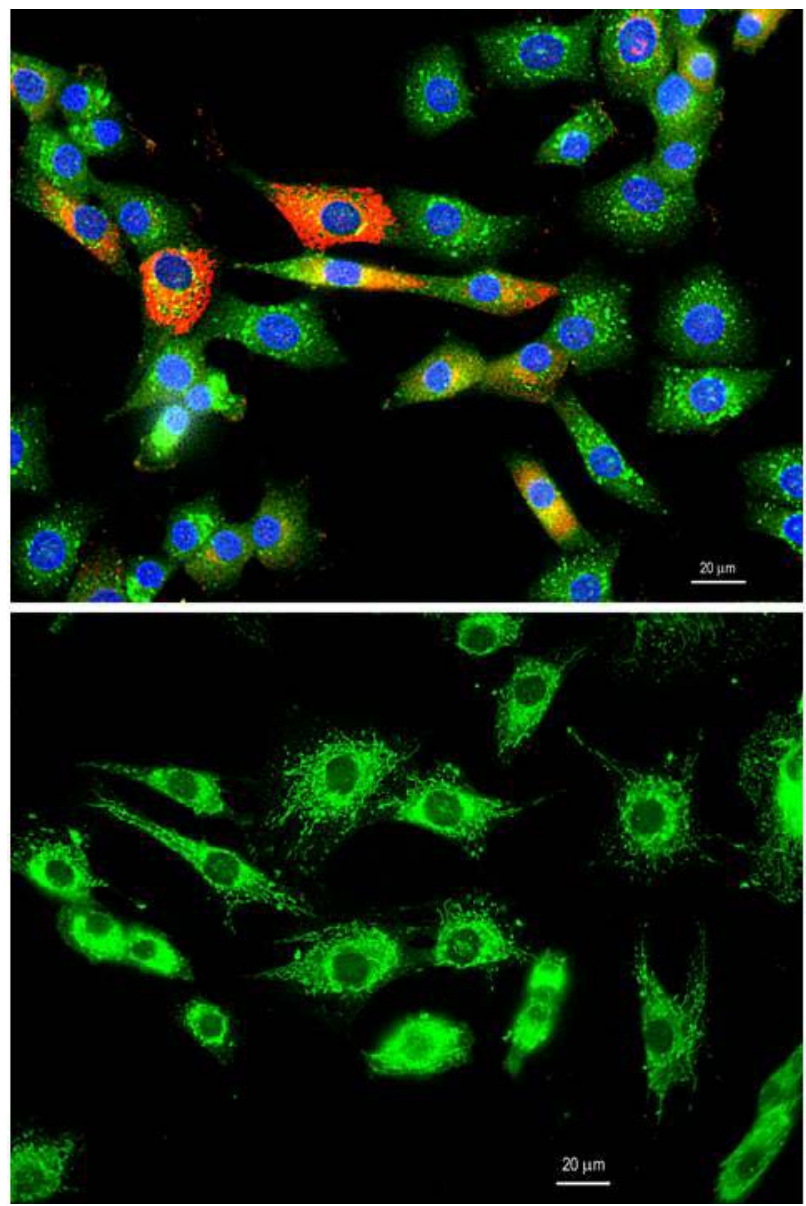

Figure 1. Representative immunofluorescent staining of collagen and aggrecan in equine chondrocytes at passage 3 monolayer culture. Equine chondrocytes stained green for type II collagen, red for type I collagen (top image) and green for aggrecan (bottom image). DAPI nuclear staining is blue (top and bottom image). Magnification indicated by bar $=20 \mu$.

stained for type I collagen alone and some stained for both (Figure 1, top image). Collagen types I and II (Figure 1, top image) were colocalized in the peri-nuclear cytoplasm. In comparison, all chondrocytes immunostained for aggrecan (Figure 1, bottom image). Chondrocyte morphology varied from the more rounded to spindle shape.

\subsection{Stimulation of Chondrocyte MCP-1 and $\mathrm{PGE}_{2}$ Production by IL- $1 \beta$ and LPS}

Stimulation of MCP-1 and $\mathrm{PGE}_{2}$ production by IL- $1 \beta$ was confirmed in chondrocyte cell lines 1 - 3 (Figure 2) and in chondrocytes cell lines 4 - 6 by LPS (Figure 3). Untreated control chondrocytes produced MCP-1 concentrations ranging from $10-25 \times 10^{3} \mathrm{pg} / \mathrm{ml}$ which significantly increased $5-7$ times with IL- $1 \beta$ stimulation, $\mathrm{p}<0.001$ (Figure 2 , left panel). Lines $1-3$ also produced variable baseline levels of $\mathrm{PGE}_{2}$ ranging from $1-16 \times 10^{2} \mathrm{pg} / \mathrm{ml}$ which significantly increased 8 - 28 times with IL- $1 \beta$ stimulation, $\mathrm{p}<0.001$ (Figure 2 , right panel). 

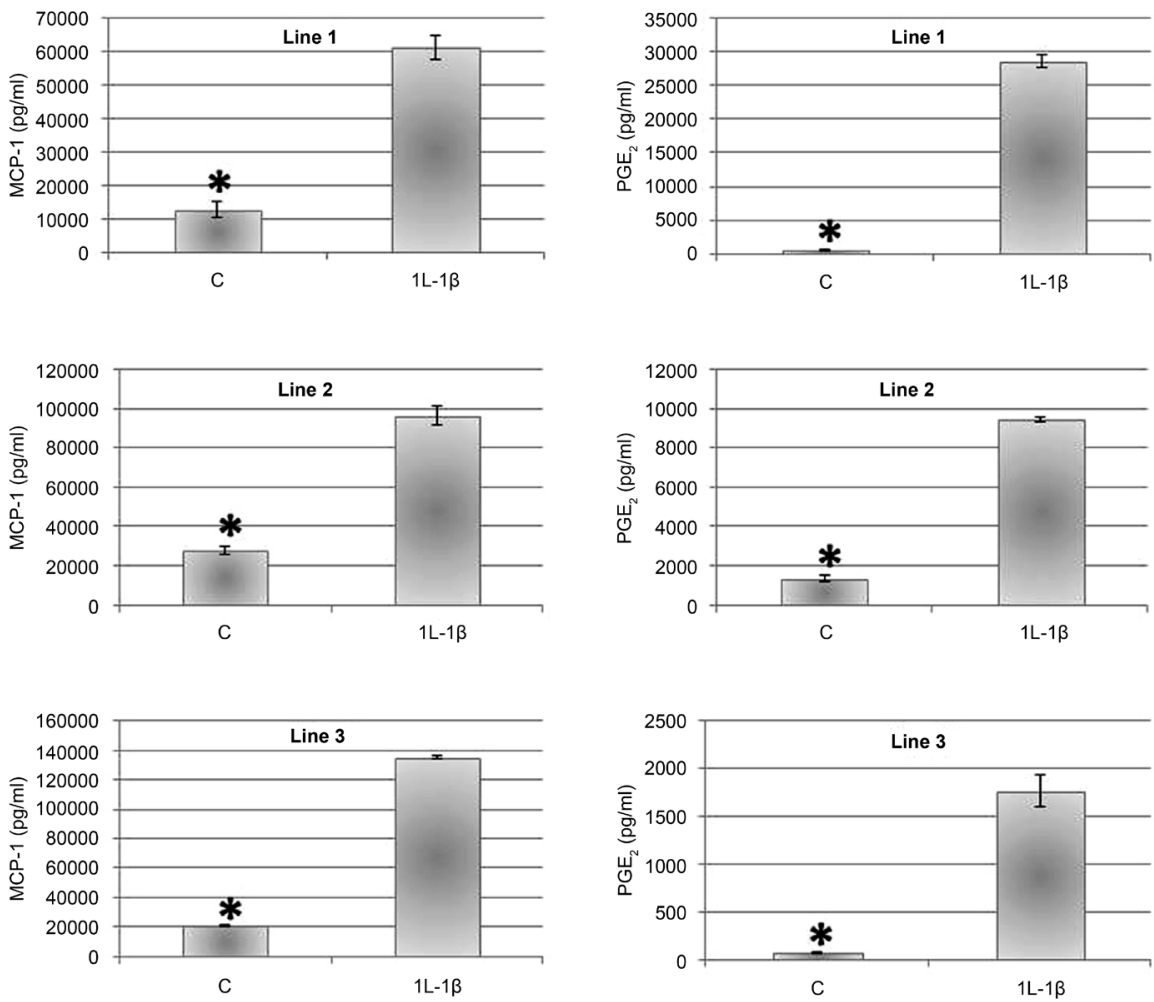

Figure 2. MCP-1 and $\mathrm{PGE}_{2}$ production by chondrocyte lines 1 - 3 following stimulation with IL- $1 \beta$. MCP-1 and $\mathrm{PGE}_{2}$ were measured in cell culture supernatant following incubation with IL- $1 \beta$ for 24 hours. Concentrations of both MCP-1 (left panel) and PGE $_{2}$ (right panel) were significantly increased following IL- $1 \beta$ stimulation compared to control cells. Results are presented as means $\pm 1 \mathrm{SD}, \mathrm{n}=3 .{ }^{*}$ indicates $\mathrm{p}<0.001$.

LPS stimulation significantly increased MCP-1 production in chondrocyte cell lines $4-6, p<0.001$ (Figure 3 left panel). Control, non-stimulated chondrocytes produced MCP- 1 concentrations ranging from 4 to $35 \times 10^{3} \mathrm{pg} / \mathrm{ml}$ which significantly increased 3 to 6 times after LPS stimulation, $\mathrm{p}<0.001$. In comparison, $\mathrm{PGE}_{2}$ production in control non-stimulated cells ranged from 4 to $35 \times 10^{3}$ $\mathrm{pg} / \mathrm{ml}$ (Figure 3, right panel). Production increased 2 to 6 times following LPS stimulation (Figure 3, right panel).

\subsection{Effect of PBZ or [ASU + GLU + CS] on MCP-1 and $\mathrm{PGE}_{2}$ Production}

Pre-treatment with [ASU + GLU + CS] or PBZ significantly inhibited $\mathrm{PGE}_{2}$ production in chondrocyte cell lines 7 and 8 stimulated with IL- $1 \beta$, and in line 9 stimulated with LPS (Figure 4). Treatment with [ASU + GLU + CS] significantly reduced $\mathrm{PGE}_{2}$ production by $\left.46 \%-60 \%, \mathrm{p}<0.001\right)$. In contrast, $\mathrm{PBZ}$ ablated $\mathrm{PGE}_{2}$ production by $97 \%-99 \%, \mathrm{p}<0.001$ (Figure 4). MCP-1 production was significantly inhibited by pre-treatment with [ASU + GLU + CS] in chondrocyte cell lines 7 and 8 stimulated with IL- $1 \beta$, and in cell line 9 stimulated with LPS (Figure 5). It is striking that PBZ did not suppress MCP-1 production whereas [ASU + GLU + CS] reduced MCP-1 levels by $30 \%-41 \%$ in stimulated cells, $\mathrm{p}<0.001$ 

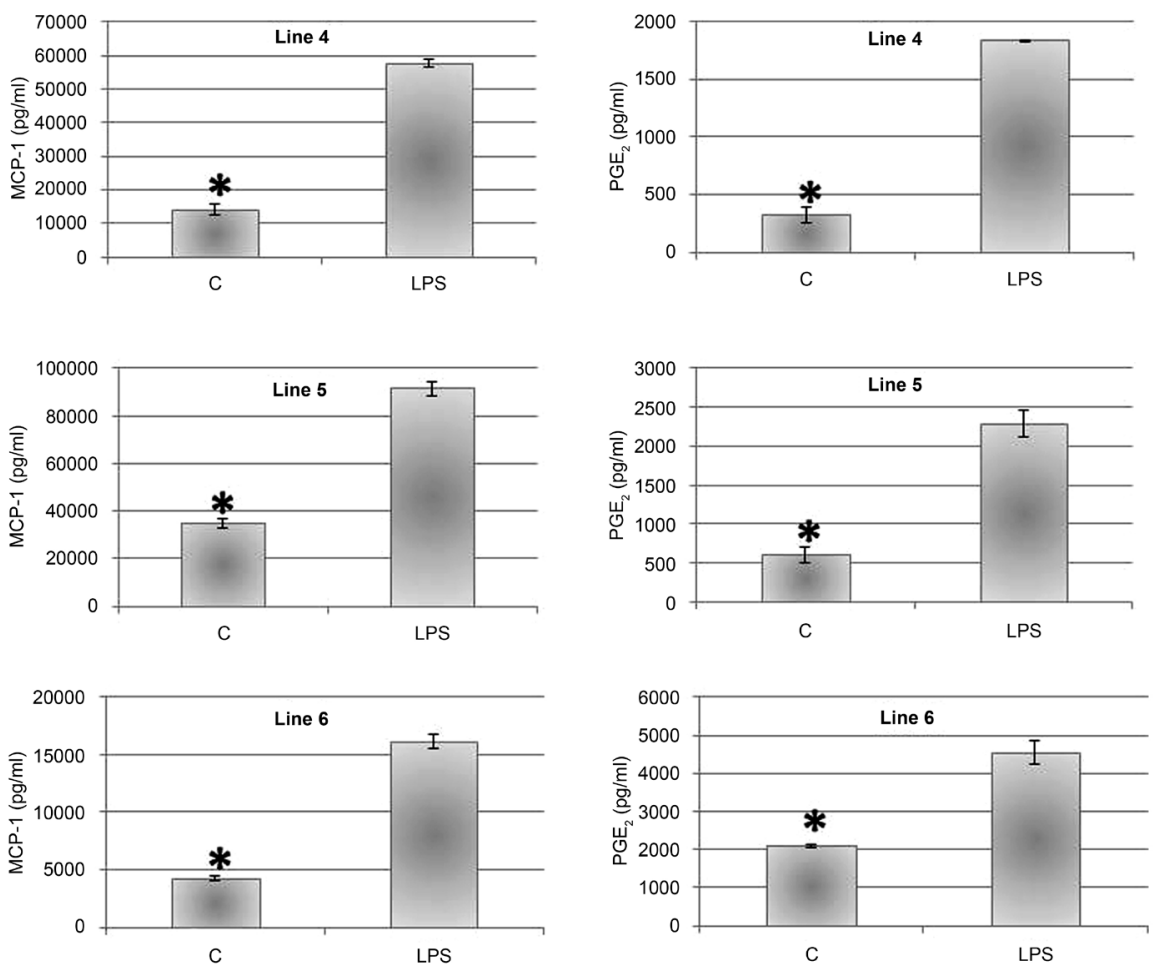

Figure 3. MCP-1 and $\mathrm{PGE}_{2}$ production by chondrocytes lines 4 - 6 following stimulation with LPS. MCP-1 and PGE $_{2}$ were measured in cell culture supernatant following incubation with LPS for 24 hours. Concentrations of both MCP-1 (left panel) and PGE 2 (right panel) were significantly increased following LPS stimulation compared to control cells. Results are presented as means $\pm 1 \mathrm{SD}, \mathrm{n}=3$. ${ }^{*}$ indicates $\mathrm{p}<0.001$.

(Figure 5). PBZ increased MCP-1 production slightly in all cultures; however this was not statistically significant (Figure 5).

\subsection{Effect of PBZ or $[\mathrm{ASU}+\mathrm{GLU}+\mathrm{CS}]$ on NF- $\kappa$ B Nuclear Translocation}

The association between inhibition of MCP-1 and $\mathrm{PGE}_{2}$ production and suppression of NF- $\kappa \mathrm{B}$ activation was analyzed using immunostaining. Chondrocytes seeded on 8-well chamber slides were pre-treated with [ASU + GLU + CS] or PBZ and then stimulated with IL- $1 \beta$ and then immunostained for NF- $\kappa$ B. Non-stimulated, control cells showed cytoplasmic fluorescence, and no nuclear fluorescence with NF- $\kappa \mathrm{B}$ immunostaining. IL- $1 \beta$ stimulated chondrocytes showed increased nuclear fluorescence, indicative of translocation of NF- $\kappa \mathrm{B}$ from the cytoplasm to the nucleus. Pre-treatment with [ASU + GLU + CS] or PBZ diminished nuclear fluorescence in IL-1 $\beta$ stimulated cells (Figure 6).

\section{Discussion}

The principal finding of the present study is that [ASU + GLU + CS] inhibits MCP-1 and $\mathrm{PGE}_{2}$ production whereas PBZ ablates $\mathrm{PGE}_{2}$ levels but has minimal effect on MCP-1 levels. We used equine chondrocytes in monolayer culture since they display phenotypic changes similar to those of osteoarthritic cartilage. 


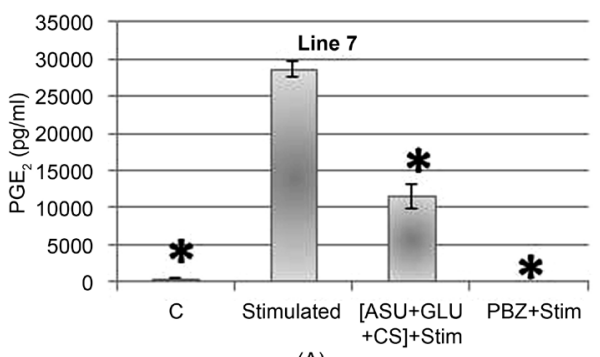

(A)
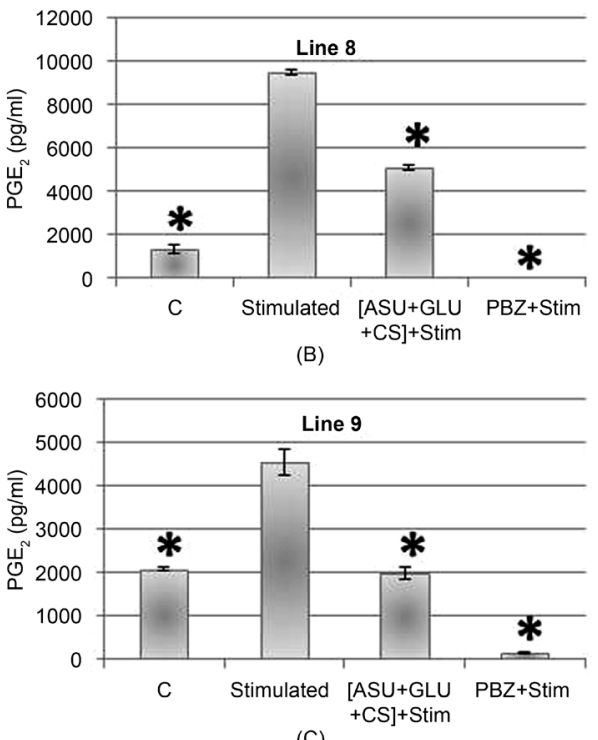

(C)

Figure 4. $\mathrm{PGE}_{2}$ production following pre-treatment with [ASU + GLU + CS] or PBZ and stimulation with IL- $1 \beta$ by chondrocytes lines $7-8$, or LPS by chondrocytes line 9. Pre-treatment of cells with $[\mathrm{ASU}+\mathrm{GLU}+\mathrm{CS}]$ or PBZ significantly reduced $\mathrm{PGE}_{2}$ production in stimulated cells. Results are presented as means $\pm 1 \mathrm{SD}, \mathrm{n}$ $=3$. ${ }^{*}$ indicates $\mathrm{p}<0.001$.

Chondrocytes shift from producing the articular cartilage phenotype marker type II collagen to the fibroblastic-osteoblastic type I collagen observed in osteoarthritic cartilage. At passage 2 - 4, some chondrocytes produce type II while some produce either type I collagen alone or both (Figure 1). These chondrocyte cultures also showed robust response to IL- $1 \beta$ and LPS stimulation indicated by significant increase in $\mathrm{MCP}-1$ andPGE 2 production confirming earlier reports (Figures 2, Figure 3).

The finding that $[A S U+$ GLU + CS] significantly suppressed but did not totally ablate MCP-1 and $\mathrm{PGE}_{2}$ production suggests that this compound could minimize disruption of physiologic functions of these molecules (Figure 4, Figure 5). It has been reported that NSAIDs that totally block $\mathrm{PGE}_{2}$ production interfere with bone healing and fracture repair [28] [29] [30]. Although $\mathrm{PGE}_{2}$ is well-characterized for its key role in the pathogenesis of $\mathrm{OA}, \mathrm{PGE}_{2}$ is also critical for healing and tissue repair [28] [29] [30]. While sparing the physiologic functions of $\mathrm{PGE}_{2}$, [ASU + GLU + CS] could effectively inhibit the ability of $\mathrm{PGE}_{2}$ to 1) stimulate the production of degradative enzymes and 2) suppress the synthesis 


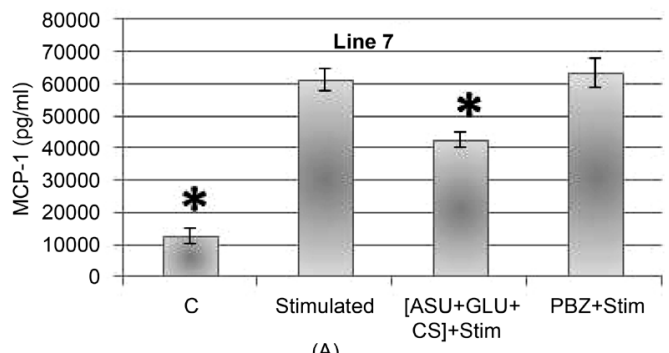

(A)

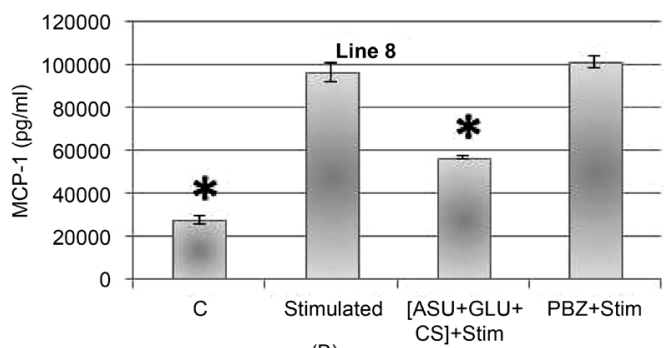

(B)

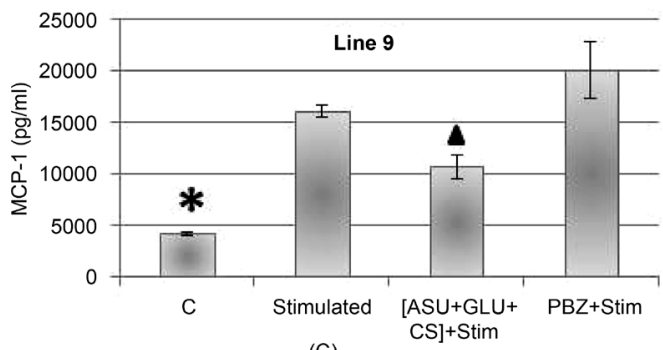

(C)

Figure 5. MCP-1 production following pre-treatment with [ASU + GLU + CS] or PBZ and stimulation with IL- $1 \beta$ by chondrocytes lines $7-8$, or LPS by chondrocytes line 9. Pre-treatment of cells with $[$ ASU + GLU + CS] significantly reduced MCP-1 production but not with PBZ in stimulated cells $(\mathrm{p}>0.05)$. Results are presented as means $\pm 1 \mathrm{SD}, \mathrm{n}=3$. ${ }^{*}$ indicates $\left.\mathrm{p}<0.001\right), \boldsymbol{\Delta}$ indicates $\mathrm{p}=0.011$.

of cartilage extracellular matrix components, as well as attenuate induction of other pro-inflammatory mediators [18]. More importantly [ASU + GLU + CS] could minimize $\mathrm{PGE}_{2}$ mediated sensitization of pain nociceptors [20]-[26].

Similarly, [ASU + GLU + CS] suppresses but does not ablate MCP-1 production in stimulated chondrocytes. This compound could thus help preserve physiologic biologic functions of $\mathrm{MCP}-1$ while modifying its deleterious participation in OA pathogenesis. MCP-1 expression which was reported to induce MMPs in osteoarthritic patients has been correlated with severity of the disease [24] [25] [26]. In vitro treatment of human chondrocytes with exogenous MCP-1 results in significant MMP-3 production. MMP-3 is an important catabolic enzyme that has been linked to pain induction in OA. This conclusion is supported by a study which showed reduction in movement-related pain behavior in CCR2 knockout mice compared to wild-type mice with experimentally induced OA [21]. However, osteoarthritic pain attributed to MCP-1 may not involve degradation of cartilage matrix and tissue destruction.

$\mathrm{PBZ}$ profoundly suppressed $\mathrm{PGE}_{2}$ production in chondrocytes stimulated with 

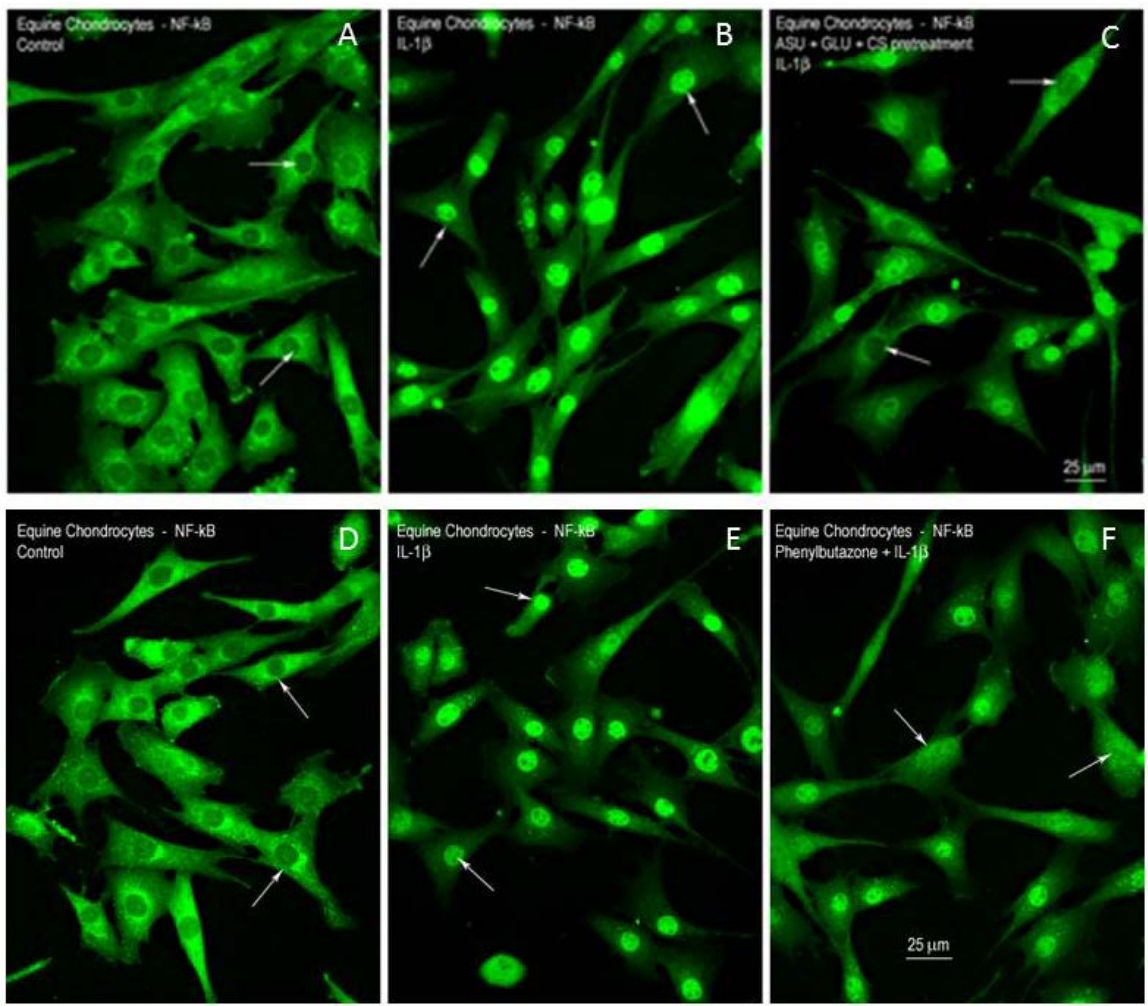

Figure 6. NF- $\kappa \mathrm{B}$ immunofluorescence in stimulated and pre-treated cells. Control cells $(\mathrm{A}, \mathrm{D})$ show cytoplasmic fluorescence, and no nuclear fluorescence with NF- $\kappa$ B. Stimulation of cells with IL- $1 \beta$ (B, E) increases nuclear fluorescence, indicative of nuclear translocation of NF- $\kappa$ B. Pre-treatment of cells with $[\mathrm{ASU}+\mathrm{GLU}+\mathrm{CS}](\mathrm{C})$ or PBZ (F) diminished nuclear fluorescence following IL-1 $\beta$ stimulation. Arrows point to nuclei. Magnification indicated by bar $=25 \mu$.

IL- $\beta$ or LPS (Figure 4). Notably, PBZ did not inhibit MCP-1 production in equine chondrocytes compared to [ASU + GLU + CS] (Figure 5). This observation suggests that the inhibitory effect on MCP-1 by [ASU + GLU + CS] could be regulated along different pathways. Further support of this possibility is the observation that both PBZ and [ASU + GLU + CS] inhibited nuclear translocation of NF- $\kappa$ B (Figure 6), but did not result in concomitant suppression of MCP-1 production by PBZ. Previous studies have shown that ASU, GLU and CS individually or in combination with other agents inhibit NF- $k$ B translocation [38] [47]-[52]. NF- $\kappa \mathrm{B}$ is well known as a critical regulator of the inflammatory response in chondrocytes including $\mathrm{PGE}_{2}$ production and expression of enzymes that degrade cartilage matrix [38] [47] [48] [49] [50] [51].

It is now acknowledged that the pathogenesis of OA involves a wide variety of inflammatory mediators. Among the mediators receiving increasing attention are chemokines such as MCP-1 that are suspected to induce pain in the joint. Understanding of how production of these mediators can be suppressed and how their inhibition may affect OA pathology is still limited. As demonstrated in this study, commonly used therapeutics, such as non-steroidal anti-inflammatory drugs (NSAIDs), may not be able to attenuate production of all relevant inflam- 
matory mediators. The observation that $[\mathrm{ASU}+\mathrm{GLU}+\mathrm{CS}]$ and PBZ differ in their effect on MCP-1 in stimulated horse chondrocytes may be of practical significance since MCP-1and its receptors have been implicated in the pathogenesis of OA. The data from this study suggest that the combination of [ASU + GLU + CS] may have broader effects than PBZ alone.

\section{Conclusion}

This study provides evidence that the inhibition of MCP-1 can be a specific target for therapeutic intervention. Targeting multiple pathways leading to inflammation and joint destruction may offer a more effective treatment. Further studies using OA cartilage and in vivo techniques would be useful to determine the full extent of MCP-1 production in osteoarthritic joints. Additionally, studies looking at combination treatment with [ASU + GLU + CS] and PBZ are warranted following the results from this study. Combination treatment may result in greater reduction of the inflammatory response. Alternatively, combination treatment may allow for the use of lower doses of PBZ or other NSAIDs clinically, therefore reducing the risk of adverse effects associated with NSAID use in horses and man, such as gastrointestinal ulceration and renal damage. Further work to elucidate the downstream effects of MCP-1 would be useful to determine the need for additional treatment options.

\section{Acknowledgements}

This study was supported by Nutramax Laboratories, Inc. We would like to thank Dr. Reinhard Grzanna for designing the immunohistochemistry and Western blot experiments as well as for constructive review of the manuscript and Lowella Fortuno for technical assistance.

\section{Competing Interests}

Carmelita G. Frondoza, Ph. D. and Mark Grzanna, MS are former employees of Nutramax Laboratories, Inc. but do not hold stocks or royalties. Erica J Secor, DVM, MS and Ann M. Rashmir-Raven, DVM do not have competing interests.

\section{References}

[1] Arthritis Foundation (2015) Osteoarthritis. http://www.arthritis.org/conditions-treatments/disease-center/osteoarthritis/

[2] Cross, M., Smith, E., Hoy, D., Nolte, S., Ackerman, I., Fransen, M., Bridgett, L., Williams, S., Guillemin, F., Hill, C.L., Laslett, L.L., Jones, G., Cicuttini, F., Osborne, R., Vos, T., Buchbinder, R., Woolf, A. and March, L. (2015) The Global Burden of Hip and Knee Osteoarthritis: Estimates from the Global Burden of Disease 2010 Study. Annals of the Rheumatic Diseases, 73, 1323-1330. https://doi.org/10.1136/annrheumdis-2013-204763

[3] Caron, J. and Genovese, R. (2003) Principles and Practices of Joint Disease Treatment. In: Diagnosis and Management of Lameness in the Horse. 2nd Edition, WB Saunders Co., Philadelphia, 746-664. https://doi.org/10.1016/B978-0-7216-8342-3.50092-9 
[4] Neundorf, R.H., Lowerison, M.B., Cruz, A.M., Thomason, J.J., McEwen, B.J. and Hurtig, M.B. (2010) Determination of the Prevalence and Severity of Metacarpophalangeal Joint Osteoarthritis in Thoroughbred Racehorses via Quantitative Macroscopic Evaluation. American Journal of Veterinary Research, 71, 1284-1293. https://doi.org/10.2460/ajvr.71.11.1284

[5] Mcllwraith, C.W., Frisbie, D.D. and Kawcak. (2012) The Horse as a Model of Naturally Occurring Osteoarthritis. Bone \& Joint Research, 1, 297-309. https://doi.org/10.1302/2046-3758.111.2000132

[6] Malda, J., Benders, K.E.M., Klein, T.J., de Grauw, J.C., Kik, M.J., Hutmacher, DW., Saris, D.B., van Weeren, P.R. and Dhert, W.J. (2012) Comparative Study of Depth-Dependent Characteristics of Equine and Human Osteochondral Tissue from the Medial and Lateral Femoral Condyle. Osteoarthritis Cartilage, 20, 1147-1151. https://doi.org/10.1016/j.joca.2012.06.005

[7] Svala, E, Löfgren, M., Sihlbom, C., Rüetschi, U., Lindahl, A., Ekman, S. and Skiöldebrand, E. (2016) An Inflammatory Equine Model Demonstrates Dynamic Changes of Immune Response and Cartilage Matrix Molecule Degradation in vitro. Connective Tissue Research, 56, 315-325. https://doi.org/10.3109/03008207.2015.1027340

[8] Tung, J.T., Venta, P.J., Eberhart, S.W., Yuzbasiyan-Gurkan, V., Alexander, L., Caron, J. and Palda, J. (2002) Effects of Anti-Arthritis Preparations on Gene Expression and Enzyme Activity of Cyclooxygenase-2 in Cultured Equine Chondrocytes. American Journal of Veterinary Research, 63, 1134-1139. https://doi.org/10.2460/ajvr.2002.63.1134

[9] Heinecke, L.F., Grzanna, M.W., Au, A.Y., Mochal, C.A., Rashmir-Raven, A. and Frondoza, C.G. (2010) Inhibition of Cyclooxygenase-2 Expression and Prostaglandin E2 Production in Chondrocytes by Avocado Soybean Unsaponifiables and Epigallocatechin Gallate. Osteoarthritis Cartilage, 18, 220-227. https://doi.org/10.1016/j.joca.2009.08.015

[10] Ownby, S.L., Fortuno, L.V., Au, A.Y., Grzanna, M.W., Rashmir-Raven, A.M. and Frondoza, C.G. (2014) Expression of Pro-Inflammatory Mediators Is Inhibited by an Avocado/Soybean Unsaponifiables and Epigallocatechin Gallate Combination. Journal of Inflammation (London), 11, 8. https://doi.org/10.1186/1476-9255-11-8

[11] Frondoza, C.G., Fortuno, L.V., Grzanna, M.W., Ownby, S.L., Au, A.Y. and Rashmir-Raven, A.M. (2017) a-Lipoic Acid Potentiates the Anti-Inflammatory Activity of Avocado/Soybean Unsaponifiables in Chondrocyte Cultures. Cartilage, 1-9. https://doi.org/10.1177/1947603516686146

[12] David, F., Farley, J., Huang, H., Lavoie, J.P, and Laverty, S. (2007) Cytokine and Chemokine Gene Expression of IL-1 $\beta$ Stimulated Equine Articular Chondrocytes. Veterinary Surgery, 36, 221-227. https://doi.org/10.1111/j.1532-950X.2007.00253.x

[13] Bertone, A.L., Palmer, J.L. and Jones, J. (2001) Synovial Fluid Cytokines and Eicosanoids as Markers of Joint Disease in Horses. Veterinary Surgery, 30, 528-538. https://doi.org/10.1053/jvet.2001.28430

[14] Attur, M., Al-Mussawir, H.E., Patel, J., Kitay, A., Dave, M., Palmer, G., Pillinger, M.H. and Abramson, S.B. (2008) Prostaglandin $E_{2}$ Exerts Catabolic Effects in Osteoarthritis Cartilage: Evidence for Signaling via the EP4 Receptor. Journal of Immunology, 181, 5082-5088.

[15] Goldring, M.B. and Otero, M. (2011) Inflammation in Osteoarthritis. Current Opinion in Rheumatology, 23, 471-478. https://doi.org/10.1097/BOR.0b013e328349c2b1

[16] Kapoor, M., Martel-Pelletier, J., Lajeunesse, D., Pelletier, J.P. and Fahmi, H. (2011) 
Role of Pro-Inflammatory Cytokines in the Pathophysiology of Osteoarthritis. Nature Reviews Rheumatology, 7, 33-32. https://doi.org/10.1038/nrrheum.2010.196

[17] Yuan, G.H., Masuko-Hongo, K., Sakata, M., Tsuruha, J., Onuma, H., Nakamura, H., Aoki, H., Kato, T. and Nishioka, K. (2001) The Role of C-C Chemokines and Their Receptors in Osteoarthritis. Arthritis \& Rheumatology, 44, 1056-1570. https://doi.org/10.1002/1529-0131(200105)44:5<1056::AID-ANR186>3.0.CO;2-U

[18] Borzì, R.M., Mazzetti, I., Cattini, L., Uguccioni, M., Baggiolini, M. and Facchini, A. (2000) Human Chondrocytes Express Functional Chemokine Receptors and Release Matrix-Degrading Enzymes in Response to C-X-C and C-C Chemokines. Arthritis \& Rheumatology, 43, 1734-1741. https://doi.org/10.1002/1529-0131(200008)43:8<1734::AID-ANR9>3.0.CO;2-B

[19] Sandell, L.J., Xing, X., Franz, C., Davies, S., Chang, L.W. and Patra, D. (2008) Exuberant Expression of Chemokine Genes by Adult Human Articular Chondrocytes in Response to IL-1 $\beta$. Osteoarthritis Cartilage, 16, 1560-1571. https://doi.org/10.1016/j.joca.2008.04.027

[20] Eitner, A., Hofmann, G.O. and Schaible, H.G. (2017) Mechanisms of Osteoarthritic Pain. Studies in Humans and Experimental Models. Frontiers in Molecular Neuroscience, 10, 349. https://doi.org/10.3389/fnmol.2017.00349

[21] Abbadie, C., Lindia, J.A., Cumiskey, A.M., Peterson, L.B., Mudgett, J.S., Bayne, E.K., DeMartino, J.A., MacIntyre, D.E. and Forrest, M.J. (2003) Impaired Neuropathic Pain Responses in Mice Lacking the Chemokine Receptor CCR2. Proceedings of the National Academy of Sciences, 100, 7947-7952. https://doi.org/10.1073/pnas.1331358100

[22] White, F.A., Sun, J., Waters, S.M., Ma, C., Ren, D., Ripsch, M., Steflik, J., Cortright, D.N., Lamotte, R.H. and Miller, R.J. (2005) Excitatory Monocyte Chemoattractant Protein-1 Signaling Is Up-Regulated in Sensory Neurons after Chronic Compression of the Dorsal Root Ganglion. Proceedings of the National Academy of Sciences, 102, 14092-14097. https://doi.org/10.1073/pnas.0503496102

[23] Jung, H., Toth, P.T., White, F.A. and Miller, R.J. (2008) Monocyte Chemoattractant Protein-1 Functions as a Neuromodulator in the Dorsal Root Ganglia Neurons. Journal of Neurochemistry, 104, 254-263.

[24] Lee, A.S., Ellman, M.B., Yan, D., Kroin, J.S., Cole, B.J., van Wijnen, A.J. and Im, H.J. (2013) Current Review of Molecular Mechanisms Regarding Osteoarthritis and Pain. Gene, 527, 440-447. https://doi.org/10.1016/j.gene.2013.05.069

[25] Miller, R.E., Miller, R.J. and Malfait, A.M. (2014) Osteoarthritis Joint Pain: The Cytokine Connection. Cytokine, 70, 185-193. https://doi.org/10.1016/j.cyto.2014.06.019

[26] Scanzello, C.R. (2017) Chemokines and Inflammation in Osteoarthritis: Insights from Patients and Animal Models. Journal of Orthopaedic Research, 35, 735-739. https://doi.org/10.1002/jor.23471

[27] Loveless, M.S. and Fry, A.L. (2016) Pharmacologic Therapies in Musculoskeletal Conditions. Medical Clinics of North America, 10, 869-890. https://doi.org/10.1016/j.mcna.2016.03.015

[28] Geusens, P., Emans, P.J., de Jong, J.J. and van den Bergh, J. (2013) NSAIDs and Fracture Healing. Current Opinion in Rheumatology, 25, 524-531. https://doi.org/10.1097/BOR.0b013e32836200b8

[29] Wixted, J.J., Fanning, P.F., Rothkopf, I., Stein, G. and Lian, J. (2010) Arachidonic Acid, Eicosanoids, and Fracture Repair. Journal of Orthopaedic Trauma, 24, 539-542. 
[30] Kalish, B.T., Kieran, M.W., Puder, M. and Panigrahy, D. (2013) The Growing Role of Eicosanoids in Tissue Regeneration, Repair, and Wound Healing. Prostaglandins \& Other Lipid Mediators, 104-105, 130-138. https://doi.org/10.1016/j.prostaglandins.2013.05.002

[31] Henrotin, Y.E., Sanchez, C., Deberg, M.A., Piccardi, N., Guillou, G.B., Msika, P. and Reginster, J.Y. (2003) Avocado/Soybean Unsaponifiables Increase Aggrecan Synthesis and Reduce Catabolic and Proinflammatory Mediator Production by Human Osteoarthritic Chondrocytes. The Journal of Rheumatology, 30, 1825-1834.

[32] Au, R.Y., Al-Talib, T.K., Au, A.Y., Phan, P.V. and Frondoza, C.G. (2007) Avocado Soybean Unsaponifiables (ASU) Suppress TNF- $\alpha$, IL-1 $\mathcal{B}$, COX-2, and i-NOS Gene Expression, and Prostaglandin E2 and Nitric Oxide Production in Articular Chondrocytes and Monocyte/Macrophages. Osteoarthritis Cartilage, 15, 1249-1255. https://doi.org/10.1016/j.joca.2007.07.009

[33] Gabay, O., Gosset, M., Lev, A., Salvat, C., Sanchez, C., Pigenet, A., Sautet, A., Jacques, C. and Berenbaum, F. (2008) Stress-Induced Signaling Pathways in Hyalin Chondrocytes: Inhibition by Avocado-Soybean Unsaponifiables (ASU). Osteoarthritis and Cartilage, 16, 373-384. https://doi.org/10.1016/j.joca.2007.06.016

[34] Lippiello, L., Nardo, J.V., Harlan, R. and Chiou, T. (2008) Metabolic Effects of Avocado/Soy Unsaponifiables on Articular Chondrocytes. Evidence-Based Complementary Alternative Medicine, 5, 191-197. https://doi.org/10.1093/ecam/nem132

[35] Du Souich, P., Garcia, A.G., Verges, J. and Montell, E. (2009) Immunomodulatory and Anti-Inflammatory Effects of Chondroitin Sulphate. Journal of Cellular and Molecular Medicine, 13, 1451-1463. https://doi.org/10.1111/j.1582-4934.2009.00826.x

[36] Chan, P.S., Caron, J.P. and Orth, M.W. (2005) Effect of Glucosamine and Chondroitin Sulfate on Regulation of Gene Expression of Proteolytic Enzymes and Their Inhibitors in Interleukin-1-Challanged Bovine Articular Cartilage Explants. American Journal of Veterinary Research, 66, 1870-1876. https://doi.org/10.2460/ajvr.2005.66.1870

[37] Grzanna, M.W., Ownby, S.L., Heinecke, L.F., Au, A.Y. and Frondoza, C.G. (2010) Inhibition of Cytokine Expression and Prostaglandin E2 Production in Monocyte/Macrophage-Like Cells by Avocado Soybean Unsaponifiables and Chondroitin Sulfate. Journal of Complementary and Integrative Medicine, 7, Article 10. https://doi.org/10.2202/1553-3840.1338

[38] Frondoza, C.G., Heinecke, L.F., Grzanna, M.W., Au, A.Y. and Ownby, S.L. (2011) Modulation of Cytokine-Induced Prostaglandin $\mathrm{E}_{2}$ Production in Cultures of Articular Chondrocytes Obtained from Carpal Joints of Camels (Camelus dromedarius). American Journal of Veterinary Research, 72, 51-58.

https://doi.org/10.2460/ajvr.72.1.51

[39] Henrotin, Y., Lambert, C., Couchourel, D., Ripoll, C. and Chiotelli, E. (2011) Nutraceuticals: Do They Represent a New Era in the Management of Osteoarthritis? A Narrative Review from the Lessons Taken with Five Products. Osteoarthritis Cartilage, 19, 1-21. https://doi.org/10.1016/j.joca.2010.10.017

[40] Leffler, C.T., Philippi, A.F., Leffler, S.G., Mosure, J.C. and Kim, P.D. (1999) Glucosamine, Chondroitin, and Manganese Ascorbate for Degenerative Joint Disease of the Knee or Low Back: A Randomized, Double-Blind, Placebo-Controlled Pilot Study. Military Medicine, 164, 85-91.

[41] Das, A. and Hammad, T.A. (2000) Efficacy of a Combination of FCHG49 Glucosamine Hydrochloride, TRH122 Low Molecular Weight Sodium Chondroitin Sulfate and Manganese Ascorbate in the Management of Knee Osteoarthritis. Osteoarthri- 
tis Cartilage, 8, 343-350. https://doi.org/10.1053/joca.1999.0308

[42] Provenza, J.R., Shinjo, S.K. and Silva, J.M. (2015) Combined Glucosamine and Chondroitin Sulfate, Once or Three Times Daily, Provides Clinically Relevant Analgesia in Knee Osteoarthritis. Clinical Rheumatology, 34, 1455-14620. https://doi.org/10.1007/s10067-014-2757-1

[43] Navarro, S.L., White, E. and Kantor, E.D. (2015) Randomized Trial of Glucosamine and Chondroitin Supplementation on Inflammation and Oxidative Stress Biomarkers and Plasma Proteomics Profiles in Healthy Humans. PLoS ONE, 10, e0117534. https://doi.org/10.1371/journal.pone.0117534

[44] Chen, A.L., Robbins, M.I. and Zhang, Z. (2017) The Effects of FCHG49 Glucosamine-TRH122, Chondroitin Sulfate-NMX1000 Avocado Soybean Unsaponifiables on Symptomatic Chondral Defects in Elite Ski Jumpers. Journal of Preventive Medicine \& Public Health, 1, 1017.

[45] Hochberg, M.C., Martel-Pelletier, J., Monfort, J., Möller, I., Castillo, J.R., Arden, N., Berenbaum, F., Blanco, F.J., Conaghan, P.G., Doménech, G., Henrotin, Y., Pap, T., Richette, P., Sawitzke, A., du Souich, P. and Pelletier, J.P. (2016) Combined Chondroitin Sulfate and Glucosamine for Painful Knee Osteoarthritis: A Multicentre, Randomised, Double-Blind, Non-Inferiority Trial versus Celecoxib. Annals of the Rheumatic Diseases, 75, 37-44. https://doi.org/10.1136/annrheumdis-2014-206792

[46] Wildi, L.M., Raynauld, J.P., Martel-Pelletier, J., Beaulieu, A., Bessette, L., Morin, F., Abram, F., Dorais, M. and Pelletier, J.P. (2011) Chondroitin Sulphate Reduces Both Cartilage Volume Loss and Bone Marrow Lesions in Knee Osteoarthritis Patients Starting as Early as 6 Months after Initiation of Therapy: A Randomised, Double-Blind, Placebo-Controlled Pilot Study Using MRI. Annals of the Rheumatic Diseases, 70, 982-989. https://doi.org/10.1136/ard.2010.140848

[47] Beinke, S. and Ley, S.C. (2004) Functions of NF-kB1 and NF-kB2 in Immune Cell Biology. Biochemical Journal, 382. 393-409. https://doi.org/10.1042/BJ20040544

[48] Berenbaum, F. (2004) Signaling Transduction: Target in Osteoarthritis. Current Opinion in Rheumatology, 16, 616-622. https://doi.org/10.1097/01.bor.0000133663.37352.4a

[49] Jomphe, C., Gabriac, M., Hale, T.M., Héroux, L., Trudeau, L.E., Deblois, D., Montell, E., Vergés, J. and du Souich, P. (2008) Chondroitin Sulfate Inhibits the Nuclear Translocation of Nuclear Factor- $\kappa \mathrm{B}$ in Interleukin-1 $\beta$-Stimulated Chondrocytes. Basic \& Clinical Pharmacology \& Toxicology, 102, 59-65.

[50] Largo, R., Alvarez-Soria, M.A., Díez-Ortego, I., Calvo, E., Sánchez-Pernaute, O., Egido, J. and Herrero-Beaumont, G. (2003) Glucosamine Inhibits IL-1 $\beta$-Induced NFкB Activation in Human Osteoarthritic Chondrocytes. Osteoarthritis Cartilage, 11, 290-298. https://doi.org/10.1016/S1063-4584(03)00028-1

[51] Dalirfardouei, R., Karimi, G. and Jamialahmadi, K. (2016) Molecular Mechanisms and Biomedical Applications of Glucosamine as a Potential Multifunctional Therapeutic Agent. Life Sciences, 152, 21-29. https://doi.org/10.1016/j.lfs.2016.03.028

[52] Goodrich, L.R. and Nixon, A. (2006) Medical Treatment of Osteoarthritis in the Horse-A Review. The Veterinary Journal, 171, 51-69.

https://doi.org/10.1016/j.tvjl.2004.07.008 


\section{List of Abbreviations}

MCP: monocyte chemotactic protein

PGE: prostaglandin

ASU: avocado/soybean unsaponifiables

GLU: glucosamine

CS: chondroitin sulfate

PBZ: phenylbutazone

NSAID: non-steroidal anti-inflammatory drugs

IL: interleukin

MMP: metalloproteinase

PBS: phosphate buffered saline 